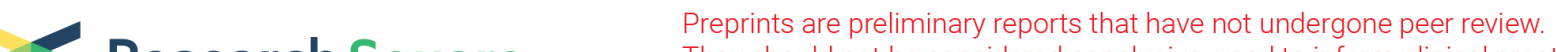 Research Square They should not be considered conclusive, used to inform clinical practice, or referenced by the media as validated information.
}

\section{Digital Immunoassay Protocol for Solid-State Nanopore Sensing}

\section{Liqun $\mathrm{He}$}

University of Ottawa https://orcid.org/0000-0002-7417-448X

Daniel R. Tessier

University of Ottawa https://orcid.org/0000-0002-9695-6204

Kyle Briggs

University of Ottawa https://orcid.org/0000-0002-0183-6585

Matthaios Tsangaris

University of Ottawa

Martin Charron

University of Ottawa

Erin M. McConnell

University of Ottawa

Dmytro Lomovtsev

University of Ottawa

Vincent Tabard-Cossa ( $\nabla$ vtabardc@uottawa.ca)

University of Ottawa https://orcid.org/0000-0003-4375-717X

\section{Method Article}

Keywords: nanopore, immunoassay, protein, digital detection, diagnostics, thyroid stimulating hormone

Posted Date: February 10th, 2022

DOl: https://doi.org/10.21203/rs.3.pex-1591/v1

License: (c) (i) This work is licensed under a Creative Commons Attribution 4.0 International License.

Read Full License 


\section{Abstract}

The ability to digitally count single molecules enables accurate and precise determination of the concentration of a disease biomarker. Owing to their intrinsic single-molecule sensitivity and fully electronic detection capability, solid-state nanopores show great promise for this task toward point-ofcare diagnostic applications. Here, we describe the protocols for implementing a magnetic bead-based immunoassay strategy coupled with digital detection and downstream solid-state nanopore electrical readout. The digital scheme employs DNA nanostructures, as proxy labels for the presence (" 1 ") or absence (" 0 ") of the target protein. We provide step-by-step protocols for assembling and purifying DNA nanostructures; Preparing magnetic beads decorated with capture antibodies; Conjugating secondary detection antibodies to bind the DNA label; Functionalizing gold nanoparticles; and Running the full assay where thyroid stimulating hormone (TSH) from human serum samples is quantified down to the femtomolar range. The protocols and assay scheme presented herein are easily generalized to the quantification of a wide range of target proteins, by selecting the appropriate antibody pair.

\section{Introduction}

\section{Reagents}

$\mathrm{SiN}_{\mathrm{x}}$ membranes (Norcada, NBPX5004Z)

SYLGARD 184 Silicone Elastomer Kit (Dow Chemical Company, 4019862)Potassium chloride (Fisher Scientific, P217-500)

Lithium Chloride (Fisher Scientific, L121-500)

Lithium Hydroxide Anhydrous (Fisher Scientific, L128-500)

HEPES (Fisher Scientific, BP310100)

Agarose (Fisher Scientific, BP160500)

Mini-PROTEAN TBE precast gels (Bio-rad, 4565013)

Mini-PROTEAN TGX gels (Bio-rad, 456-1093)

NoLimits 2kbp dsDNA fragments (ThermoFisher Scientific, SM1701)

GeneRuler 1kbp plus DNA ladder (ThermoFisher Scientific, SM1331)

DNA Gel Loading Dye 6X (ThermoFisher Scientific, R0611)

Carboxylated paramagnetic beads $2.7 \mu \mathrm{m}$ (Quanterix, 103612) 
EDC (ThermoFisher Scientific, A35391)

Sample/detector diluent (Quanterix, 101359)

Wash buffer 1 (Quanterix, 100486)

Mouse monoclonal anti human TSH beta subunit capture antibody (Fitzgerald Industries International, 10C-CR2151M4)

Anti-human TSH beta subunit detection antibody (Maine Biotechnology Services, MAB130P)

Streptavidin Conjugation Kit (Abcam, ab102921)

Recombinant TSH (rTSH) (BiosPacific, J11030)

Serum samples (BiolVT, BRH1391829 - BRH1391838)

DTT (Dithiothreitol) (ThermoFisher Scientific, A39255)

Ultramer/HPLC purified DNA oligos with modifications (Integrated DNA technologies)

Standard 30 nm gold nanoparticles (Cytodiagnostics, G-30-20)

Tween-20 (Sigma-Aldrich, P1379-100ML)

Bovine serum albumin (Proliant Biologicals, 68100-100G)

Bead Wash Buffer (Quanterix, 101355)

Bead Blocking Buffer (Quanterix, 101356)

Bead Diluent (Quanterix, 100458)

Bead Conjugation Buffer (Quanterix, 101357)

6x Loading Buffer (ThermoFisher Scientific, R0611)

5x TAEMg pH 8 (200 mM Tris, 100 mM Acetic acid, $10 \mathrm{mM}$ EDTA, and $62.5 \mathrm{mM} \mathrm{MgCl}$ )

10x TBE buffer (ThermoFisher Scientific, V36401)

10x Tris/Glycine Buffer (Bio-Rad, 1610734)

\section{Equipment}

3W LED flashlight (LIGHTFE, UV301D) 
3 kDa Amicon Ultra-0.5 Centrifugal Filter Unit (Millipore Sigma, UFC500396)

100 kDa Amicon Ultra-0.5 Centrifugal Filter Unit (Millipore Sigma, UFC510096)

D-Tube Dialyzer Maxi, MWCO 6-8 kDa (Millipore, 71509-3)

Illustra NAP-5 columns (GE Healthcare, 17185601)

Multi-Functional Tube Rotator (VWR, PTR-35).

Gel imaging workstation (Azure biosystems, C150).

MiniAmp Plus Thermal Cycler (Applied Biosystems, A37834).

VWR Mini Centrifuge (VWR, 76269-064)

\section{Procedure}

\section{DNA Nanostructure Assembly}

1. Add $12 \mu \mathrm{L}$ of each oligo (stock: $100 \mu \mathrm{M}$ ) for P1 (Star oligo 1 - 12, Extension oligo A - E, F, and G) and P2 (Star oligo 1 - 12, Extension oligo A - E, and F') in separate tubes, $72 \mu \mathrm{L}$ of 5x TAEMg buffer and deionized water to reach a total reaction volume of $360 \mu \mathrm{L}$ with a final concentration of $3.3 \mu \mathrm{M}$ for each oligo in 1x TAEMg ${ }^{1}$ (40 mM Tris, $20 \mathrm{mM}$ acetic acid, $2 \mathrm{mM}$ EDTA, and $12.5 \mathrm{mM}$ magnesium acetate, $\mathrm{pH}$ 8).

2. Vortex the samples, divide and transfer each sample into 4 PCR tubes, and place the samples in a thermal cycler such as the MiniAmp Plus Thermal Cycler (Applied Biosystems, A37834).

3. Incubate samples at $95^{\circ} \mathrm{C}$ for 5 minutes then cool to $90^{\circ} \mathrm{C}$. Ramp down from $90^{\circ} \mathrm{C}$ to $60^{\circ} \mathrm{C}$ at 0.4 ${ }^{\circ} \mathrm{C} / \mathrm{min}, 60^{\circ} \mathrm{C}$ to $26^{\circ} \mathrm{C}$ at $0.03^{\circ} \mathrm{C} / \mathrm{min}$, then snap cooled to $4{ }^{\circ} \mathrm{C}$ indefinitely.

4. Prepare $50 \mathrm{~mL} 0.5 \mathrm{x}$ TBE in an Erlenmeyer flask, weigh out and add $1 \mathrm{~g}$ of agarose to the $0.5 \mathrm{x}$ TBE buffer to make $2 \%$ gel, and microwave for 15-30 seconds at a time for approximately 2 minutes and 30 seconds until the agarose is completely dissolved. Let the agarose cool, add $5 \mu L$ of $10,000 \times$ GelRed to agarose solution, and gently mix to avoid creating bubbles. Pour the agarose solution into the gel tray, insert comb, and let agarose solidify for 20 minutes. Note: the volume of agarose and gel stain needed depends on the size of the gel plate used. For this protocol a gel tray with the following dimensions (10 $\mathrm{cm} \times 7 \mathrm{~cm}$ ) was used.

5. Pool the DNA nanostructure probes from the four PCR tubes after the assembly, mix $0.5 \mu \mathrm{L}$ of each DNA nanostructure probe with $9.5 \mu \mathrm{L}$ of deionized water and $2 \mu \mathrm{L}$ of $6 \mathrm{x}$ Loading buffer (ThermoFisher Scientific, R0611) for gel characterization. Load the samples on $2 \%$ agarose gel, run the gel at $70 \mathrm{~V}$ for 
approximately 1 hour, and visualize on Gel imaging workstation (Azure biosystems, C150). The remaining probe can be stored at $4{ }^{\circ} \mathrm{C}$.

\section{DNA Nanostructure Purification}

1. Take $90 \mu \mathrm{L}$ of assembled probe (P1/P2), add $14 \mu \mathrm{L}$ of $5 \mathrm{x}$ TAEMg, $15 \mu \mathrm{L}$ of $10 \mathrm{x}$ GelRed, $25 \mu \mathrm{L}$ of $6 \mathrm{x}$ Loading Buffer (ThermoFisher Scientific, R0611), and $26 \mu \mathrm{L}$ of deionized water. Vortex the samples and load into wells of 5\% Mini-PROTEAN TBE polyacrylamide pre-cast gels (BioRad, 4565013). Run the gel in $0.5 \times$ TBE buffer at $100 \mathrm{~V}$ on ice for 3 hours.

2. Take the gels out of cassettes and visualize using gel imager (Azure biosystems, C150) UV plate.

3. Identify the band of interest and excise with a razor blade.

4. Place the excised gel slices (containing products of interest) in custom extraction apparatus or D-Tube Dialyzer Maxi (MWCO 6-8 kDa, Millipore, 71509-3) tubes, and apply $100 \mathrm{~V}$ in 1x TBE buffer to electrophoretically extract the DNA samples out of the gel slices.

5. Take the supernatant $(0.5 \mathrm{~mL}$ to $3 \mathrm{~mL})$ from the extraction tubes, and perform buffer exchange into $1 \mathrm{x}$ TAEMg using 100 kDa Amicon Ultra-0.5 Centrifugal Filter Units (Millipore Sigma, UFC510096). This should concentrate the sample into $\sim(35 \mu \mathrm{L})$.

\section{Quantification of Nanoprobes}

6. Quantify the purified probes by taking $2 \mu \mathrm{L}$ of the sample and performing nucleic acid concentration measurements using a UV-Visible spectrophotometer for small sample volumes such as the Take3 microvolume plate accessory of the EPOC 2 spectrophotometer (BioTek, BTEPOCH2).

7. Take equimolar concentrations of purified DNA nanostructure probes, where the probe concentrations are fixed at either $15 \mathrm{nM}$ or $20 \mathrm{nM}$, and add various amounts of junction strands, ranging from $0.2 \mathrm{nM}$ (0.01:1 junction:probe) to $400 \mathrm{nM}$ (20:1 junction:probe) for dumbbell assembly.

8. Incubate for up to two days ( $48 \mathrm{~h})$ at room temperature.

9. Confirm the quality of dumbbell formation on $2 \%$ agarose gel as shown in Figure 1.

\section{Nanopore Characterization Measurements}

10. Take $4 \mu \mathrm{L}$ of the assembled dumbbell samples, add $35.5 \mu \mathrm{L}$ of $3.6 \mathrm{M} \mathrm{LiCl}$ and $0.5 \mu \mathrm{L} 2 \mathrm{kbp}$ dsDNA fragments (ThermoFisher Scientific, SM1701).

11. Vortex the sample and load it into the nanopore flow cell (cis side) ${ }^{2,3}$. 
12. Apply $-100 \mathrm{mV}$ and sense on a nanopore for 10 - 30 minutes, anticipated results are shown in Figure 2.

\section{Paramagnetic Bead Ab Conjugation}

1. Add $234 \mu \mathrm{g}$ of primary antibody (Fitzgerald Industries International, 10C-CR2151M4) to $100 \mathrm{kDa}$ Amicon Ultra-0.5 Centrifugal Filter Unit (Millipore Sigma, UFC510096).

2. Add Bead Conjugation Buffer (Quanterix, 101357) to the filter unit to reach a final volume of $500 \mu \mathrm{L}$.

3. Centrifuge at $14,000 \mathrm{~g}$ for 5 minutes, discard flow-through, and wash the samples by adding $450 \mu \mathrm{L}$ Bead Conjugation Buffer.

4. Repeat the $450 \mu \mathrm{L}$ washes three times.

5. Invert the filter unit membrane and centrifuge into a new tube at $1,000 \mathrm{~g}$ for 2 minutes.

6. Rinse the filter unit membrane by adding another $50 \mu \mathrm{L}$ of Bead Conjugation Buffer, centrifuge at 1,000 $\mathrm{g}$ for 2 minutes into the same tube.

7. Collect the sample and measure the protein concentration using the Take3 micro-volume plate accessory of the EPOC 2 spectrophotometer (BioTek, BTEPOCH2).

8. Add enough Bead Conjugation Buffer to dilute the sample to $0.3 \mathrm{mg} / \mathrm{mL}$.

9. Store the antibody sample on ice.

10. Take $300 \mu \mathrm{L}(8.5 \times 108)$ of carboxylated paramagnetic beads sized $2.7 \mu \mathrm{m}$ (Quanterix, 103612) and resuspend by vortexing.

11. Briefly centrifuge the sample using the pulse spin setting of a small 8 sample rotor bench top centrifuge and place solution on magnet for $>1$ minute, remove supernatant.

12. Add $600 \mu \mathrm{L}$ of the Bead Wash Buffer (Quanterix, 101355), and vortex to resuspend beads.

13. Repeat $600 \mu \mathrm{L}$ washes three times using Bead Wash Buffer ensuring to vortex the beads each time, then remove the buffer after the samples have been placed on the magnet for $>1 \mathrm{~min}$.

14. Add $600 \mu \mathrm{L}$ of Bead Conjugation Buffer (Quanterix, 101357), vortex to resuspend beads, then use the magnet to retain the beads and remove the buffer.

15. Repeat $600 \mu \mathrm{L}$ washes three times using Bead Conjugation Buffer (Quanterix, 101357) ensuring to vortex the beads each time, then remove the buffer after the samples have been placed on the magnet for $>1$ min. 
16. Add $570 \mu \mathrm{L}$ of the Bead Conjugation Buffer and store on ice.

17. Add $100 \mu \mathrm{L}$ of the Bead Conjugation Buffer to $1 \mathrm{mg}$ vial of EDC (ThermoFisher Scientific, A35391), close lid and vortex.

18. Add $30 \mu \mathrm{L}$ of the EDAC to the washed paramagnetic beads and incubate on shaker (VWR, PTR-35) for 30 minutes to allow for bead activation.

19. Pulse spin using tabletop centrifuge (VWR, 76269-064), and wash activated paramagnetic beads with $600 \mu \mathrm{L}$ Bead Conjugation Buffer (Quanterix, 101357), then place on magnet for $>1$ min and remove supernatant.

20. Add prepared buffer exchanged primary antibody to activated paramagnetic beads.

21. Incubate for 2 hours on shaker.

22. Pulse spin, place paramagnetic bead/primary antibody solution on magnet, collect supernatant and label as "supernatant".

23. Perform one wash with $600 \mu \mathrm{L}$ Bead Wash Buffer (Quanterix, 101355), collect supernatant and label as "wash 1".

24. Measure protein concentrations of supernatant and wash 1 using EPOC 2 spectrophotometer (BioTek, BTEPOCH2). Compare values to total amount of antibody loaded to estimate total antibody coated and percentage antibody coated.

25. Perform another wash with Bead Wash Buffer (Quanterix, 101355), then discard the supernatant.

26. Add $600 \mu \mathrm{L}$ of Bead Blocking Buffer (Quanterix, 101356) and incubate for 30 minutes on MultiFunctional Tube Rotator (VWR, PTR-35) at 5 rpm to keep particles in suspension.

27. Perform one wash using $600 \mu \mathrm{L}$ of Bead Wash Buffer (Quanterix, 101355).

28. Perform two more washes using $600 \mu \mathrm{L}$ of Bead Diluent (Quanterix, 100458), resuspend in $600 \mu \mathrm{L}$ Bead Diluent and store at $4^{\circ} \mathrm{C}$.

\section{Secondary Antibody Streptavidin Conjugation}

1. Take $62.5 \mu \mathrm{L}(100 \mu \mathrm{g})$ of secondary antibody (Maine Biotechnology Services, MAB130P) and add 37.5 $\mu \mathrm{L}$ of $1 \mathrm{x}$ PBS to have secondary antibody at $1 \mu \mathrm{g} / \mu \mathrm{L}$ in $100 \mu \mathrm{L}$.

2. Add $10 \mu \mathrm{L}$ of Modifier reagent (Abcam, ab102921) to $100 \mu \mathrm{L}$ of secondary antibody. 
3. Add the above $100 \mu \mathrm{L}$ sample to lyophilized Streptavidin Mix (Abcam, ab102921), pipette up and down to have material fully dissolved.

4. Incubate at room temperature for 3 hours.

5. Add $10 \mu \mathrm{L}$ of Quencher (Abcam, ab102921) to the reaction.

6. Incubate at room temperature for 30 minutes.

7. Confirm the quality of the conjugation using native gel, Mini-PROTEAN TGX gels (Bio-rad, 456-1093) in $1 \mathrm{x}$ Tris/Glycine Buffer at $100 \mathrm{~V}$

8. Store at $4{ }^{\circ} \mathrm{C}$.

\section{Assay Procedure}

1. Take $72 \mu \mathrm{L}(7.2 \times 107)$ of prepared bead-capture antibody conjugates, add Sample Diluent (Quanterix, 101359) to a total volume of $500 \mu \mathrm{L}$.

2. Place the tube on the magnet, and remove supernatant.

3. Perform two more $500 \mu \mathrm{L}$ washes.

4. Add various amounts ( $0.8 \mathrm{fM}$ to $1.2 \mathrm{nM}$ ) of recombinant TSH (rTSH) (BiosPacific, J11030) and bring the volume up to $500 \mu \mathrm{L}$ using Sample Diluent or diluted human serum sample.

5. Incubate for 1 hour at room temperature on Multi-Functional Tube Rotator (VWR, PTR-35) at 5 rpm.

6. Place the tube on the magnet for $>1 \mathrm{~min}$, and remove the supernatant.

7. Add $500 \mu \mathrm{L}$ of Wash Buffer 1 (Quanterix, 100486), and incubate for 5 minutes on Multi-Functional Tube Rotator (VWR, PTR-35) at $5 \mathrm{rpm}$.

8. Place the tube on the magnet for $>1 \mathrm{~min}$, and remove the supernatant.

9. Add $500 \mu \mathrm{L}$ of Wash Buffer 1 (Quanterix, 100486), and incubate for 10 minutes on Multi-Functional Tube Rotator (VWR, PTR-35) at $5 \mathrm{rpm}$.

10. Place the tube on the magnet for $>1 \mathrm{~min}$, and remove the supernatant.

11. Add $500 \mu \mathrm{L}$ of Wash Buffer 1 (Quanterix, 100486), and incubate for 15 minutes on Multi-Functional Tube Rotator (VWR, PTR-35) at $5 \mathrm{rpm}$.

12. Place the tube on the magnet for $>1 \mathrm{~min}$, and remove the supernatant. 
13. Resuspend in $500 \mu \mathrm{L}$ of Sample Diluent (Quanterix, 101359) containing $6 \mathrm{nM}$ secondary antibodystreptavidin conjugate. OPTION 1: for the amplification assay, add $10 \mu L$ of AuNP amplification complex to a final volume of $50 \mu \mathrm{L}$ in Sample Diluent (Quanterix, 101359).

14. Incubate for 1 hour on Multi-Functional Tube Rotator (VWR, PTR-35) at $5 \mathrm{rpm}$ at room temperature.

15. Perform three $30 \mathrm{sec}$ washes with $1 \mathrm{x}$ Wash Buffer 1 (Quanterix, 100486), and resuspend in $500 \mu \mathrm{L}$ of Sample Diluent (Quanterix, 101359). OPTION 1: for theamplification assay, skip this step.

16. Add $12 \mathrm{nM}$ of biotinylated ssDNA junction strand. OPTION 1: for the amplification assay, skip this step.

17. Incubate for $15 \mathrm{~min}$ at room temperature on Multi-Functional Tube Rotator (VWR, PTR-35) at $5 \mathrm{rpm}$. OPTION 1: for the amplification assay, skip this step.

18. Perform three $30 \mathrm{sec}$ washes with $1 \mathrm{x}$ Wash Buffer 1 (Quanterix, 100486), and resuspend in $500 \mu \mathrm{L}$ of 1x TAEMg buffer containing $0.025 \%$ Tween-20. OPTION 1: for the amplification assay, resuspend in 20 $\mu \mathrm{L}$ of $1 \mathrm{x}$ PBS containing $0.025 \%$ Tween- 20 .

19. Apply UV using a 3W LED flashlight (LIGHTFE, UV301D) at a distance of $1 \mathrm{~cm}$ for 20 minutes to release the sSDNA junction strand. OPTION 1: for the amplification assay, release the junction strand by incubation for 45 minutes in $0.2 \mathrm{M} \mathrm{DTT}$ (ThermoFisher Scientific, A39255) and 0.3 M NaH2PO4 buffer in a final volume of $30 \mu \mathrm{L}$.

20. Place the samples on the magnet for $>1 \mathrm{~min}$ and transfer the supernatant to $3 \mathrm{kDa}$ Amicon Ultra- 0.5 Centrifugal Filter Unit (Millipore Sigma, UFC500396).

21. Perform buffer exchange and concentrate the ssDNA junction strands into $35 \mu \mathrm{L}$ of $1 \mathrm{x}$ TAEMg containing $0.025 \%$ Tween-20.

22. Add the purified shooting star probes at either 15 or $20 \mathrm{nM}$ final concentrations.

23. Incubate at room temperate for up to 2 days for dumbbell assembly.

\section{OPTION 1: Gold Nanoparticle Amplification Scheme}

\section{DTT Reduction}


1. Take thiolated ssDNA oligos and perform three washes of $1 x$ PBS using $3 \mathrm{kDa}$ Amicon Ultra-0.5 Centrifugal Filter Unit (Millipore Sigma, UFC500396) to have final concentration of $10 \mu \mathrm{M}$ in 1x PBS.

2. Prepare 0.3 M NaH2PO4 containing0.2 M DTT solution (ThermoFisher Scientific, A39255).

3. Mix $250 \mu \mathrm{L}$ of the buffer exchanged DNA oligo and $250 \mu \mathrm{L}$ of $0.3 \mathrm{M} \mathrm{NaH} 2 \mathrm{PO} 4$ and $0.2 \mathrm{M}$ DTT.

4. Incubate at room temperature for 2 hours (unless otherwise stated incubations were done at room temperature on the benchtop.).

5. Take a NAP-5 column (GE Healthcare, 17185601), remove all caps and let storage buffer flow through.

6. Equilibrate the NAP-5 column with $10 \mathrm{~mL}$ deionized water.

7. Add the reduced DNA sample to the column and allow sample to fully enter membrane.

8. Place column on top of a new tube.

9. Add $1 \mathrm{~mL}$ deionized water to elute purified sample.

10. Reduce the volume to $200 \mu \mathrm{L}$ using $3 \mathrm{kDa}$ Amicon Ultra-0.5 Centrifugal Filter Unit (Millipore Sigma, UFC500396), confirm and adjust the final concentration of the sample to to $25 \mu \mathrm{M}$ with deionized water.

11. Split the sample into $50 \mu \mathrm{L}$ aliquots and store at $-20^{\circ} \mathrm{C}$.

\section{Preparation of Amplification complex. (AuNP Functionalization with antibody and ssDNA oligos)}

1. Take $960 \mu \mathrm{L}$ of $30 \mathrm{~nm}$ AuNP (Cytodiagnostics, G-30-20), add $40 \mu \mathrm{L} 0.1 \mathrm{M}$ borate buffer to adjust the solution to $\mathrm{pH} 9$.

2. Add $4 \mu \mathrm{g}$ of secondary antibody (Maine Biotechnology Services, MAB130P) to a $1.7 \mathrm{~mL}$ tube, and add the adjusted AuNP solution to the tube with the secondary antibody ${ }^{4,5}$.

3. Incubate at room temperature for 30 minutes.

4. Add $25 \mu \mathrm{L}$ of reduced ssDNA oligos and incubate for 1 hour.

5. Salt age to a final concentration of $0.15 \mathrm{M} \mathrm{NaCl}$ by adding 6 additions of $1 \mathrm{M} \mathrm{NaCl}$ every $30 \mathrm{~min}$.

6. Incubate at $4{ }^{\circ} \mathrm{C}$ overnight (optional pause point).

7. Add $50 \mu \mathrm{L}$ of $10 \% \mathrm{BSA}$ and incubate for 5 minutes.

8. Centrifuge at $4,500 \mathrm{~g}$ for 15 minutes. Discard the supernatant. 
9. Add $950 \mu \mathrm{L}$ of $1 \times$ PBS containing $0.025 \% \mathrm{v} / \mathrm{v}$ Tween-20, resuspend by gentle shaking or vortexing.

10. Repeat steps $8-9$ two times.

11. Add $150 \mu \mathrm{L}$ of $1 \mathrm{x}$ PBS containing $0.025 \% \mathrm{v} / \mathrm{v}$ Tween-20.

12. Store at $4{ }^{\circ} \mathrm{C}$.

\section{Troubleshooting}

\section{Time Taken}

Paramagnetic bead preparation: 5 hours

DNA nanostructure assembly: overnight

DNA nanostructure purification: 5 hours

Secondary antibody streptavidin conjugation: 4 hours

DTT reduction: 3 hours

Amplification complex preparation: 5 hours

Assay workflow: 4 hours

Dumbbell formation: up to 2 days

Nanopore sensing: $10-20$ minutes per sample

\section{Anticipated Results}

\section{References}

1. He, L., Tessier, D.R., Briggs, K. et al. Digital immunoassay for biomarker concentration quantification using solid-state nanopores. Nat Commun 12, 5348 (2021)

2. Waugh, M. et al. Solid-state nanopore fabrication by automated controlled breakdown. Nat. Protoc. 15, 122-143 (2020).

3. He, L., Karau, P. \& Tabard-Cossa, V. Fast capture and multiplexed detection of short multi-arm DNA stars in solid-state nanopores. Nanoscale 11, 16342-16350 (2019).

4. Nam, J. M., Thaxton, C. S. \& Mirkin, C. A. Nanoparticle-based bio-bar codes for the ultrasensitive detection of proteins. Science. 301, 1884-1886 (2003). 
5. Hill, H. D. \& Mirkin, C. A. The bio-barcode assay for the detection of protein and nucleic acid targets using DTT-induced ligand exchange. Nat. Protoc. 1, 324-336 (2006).

\section{Figures}

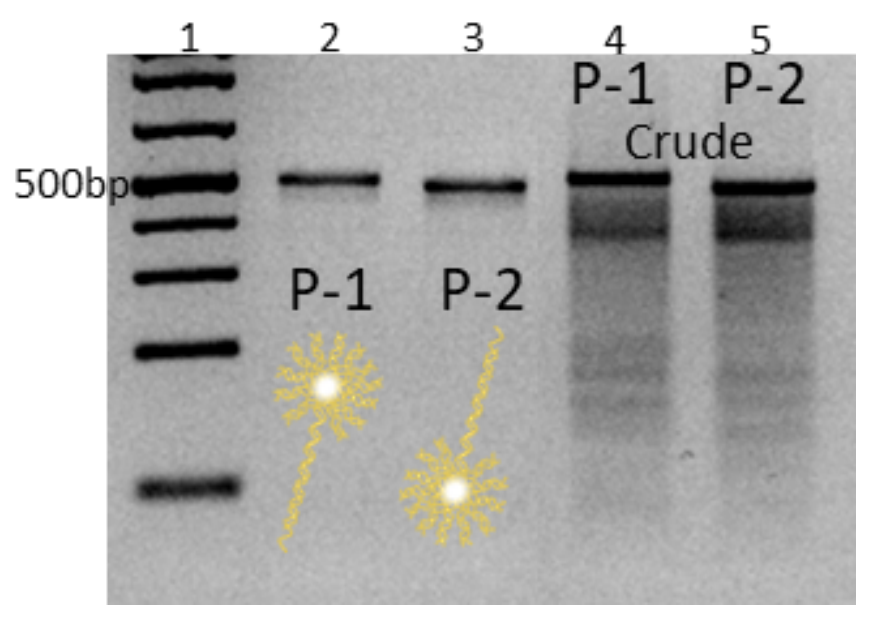

\section{Figure 1}

Agarose gel (2\%) of shooting star probes P-1 and P-2 assemblies and purification. Lane 1: GeneRuler $1 \mathrm{~kb}$ Plus DNA Ladder (ThermoFisher Scientific, SM1331), from bottom 75, 200, 300, 400, 500, 700, 1000, 1500, 2000, 3000, 4000, 5000, 7000, 10000, and 20000 bp, lane 2: gel extracted P-1, lane 3: gel extracted P-2, lane 4: crude P-1 and lane 5: crude P-2.

a

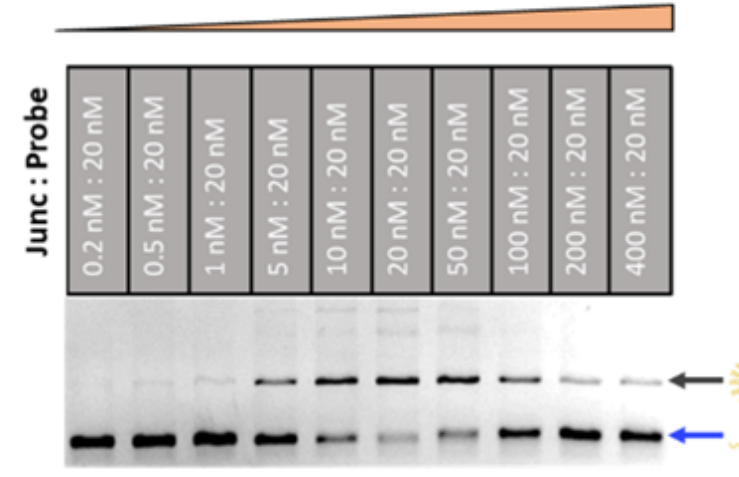

b

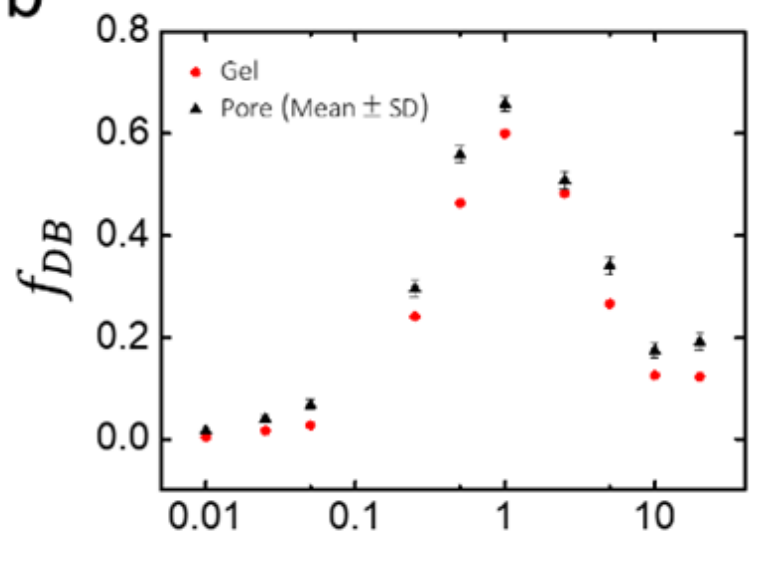

Junction Strand to Probe Ratio

\section{Figure 2}

Dose response and time dependence of dumbbell assembly. (a) Gel electrophoresis (2\% agarose) of dumbbells formation and remaining shooting star probes as junction concentration increases. (b) Comparison of dose response with junction concentration ranging from $0.2 \mathrm{nM}$ to $400 \mathrm{nM}$ (junction to shooting star probes ratio of $0.01: 1$ to $20: 1$ ) between nanopore sensing and gel band densitometry. 